\title{
Sexually Transmitted Disorder
}

National Cancer Institute

\section{Source}

National Cancer Institute. Sexually Transmitted Disorder. NCI Thesaurus. Code C3365.

A disorder acquired through sexual contact. 